\title{
Comparing the use of computer-supported collabo- ration tools among university students with different life circumstances
}

\author{
Miikka J . Eriksson \\ E-mail: miikka.eriksson@uef.fi \\ Päivi Rasi \\ E-mail: paivi.rasi@ulapland.fi \\ Hanna Vuojärvi* \\ E-mail: hanna.vuojarvi@ulapland.fi \\ Postal address for correspondence author: \\ University of Lapland / Faculty of Education \\ Hanna Vuojärvi \\ PO Box 122 \\ FI-96101 Rovaniemi, FINLAND
}

\begin{abstract}
The proportion of higher education students who integrate learning with various life circumstances such as employment or raising children is increasing. This study aims to compare whether and what kinds of differences exist between the perceived use of synchronous and asynchronous computermediated communication tools among university students with children or in full-time employment and students without these commitments. The data were collected in a Finnish University by the means of an online questionnaire. The results indicate that students with multiple commitments were using more virtual learning environments and less instant messaging (IM) especially when communicating with their peers. The low level of IM might be an indication of not being able to or not wanting to create close ties with their peer students. The practical implication of the study is that pedagogical choices should support different kinds of learning strategies. Students with multiple commitments, and especially students with children, should be encouraged and assisted to create stronger ties with their peers, if they are willing to do so.
\end{abstract}

Keywords: computer-mediated communication; university students with commitments, higher education, students' use of information and communication technologies

\section{Introduction}

The proportion of higher education students who integrate learning with various life circumstances such as employment or raising children is increasing (Broadbridge \& Swanson, 2007). These commitments might limit the opportunities to participate in classes and extracurricular student activities as well as to interact with peers and instructors (Graham \& Donaldson, 1999).

A low level of academic and social integration can have negative effects on the progress of students' studies and degree completion (Tinto \& Pusser, 2006). In their review of the literature on the conditions within universities that are 
needed to promote student success (defined as the completion of a college degree), Tinto and Pusser (2006) concluded that "the key concept is that of educational community and the capacity of institutions to establish educational communities that involve all students as equal members" (p. 8).

The literature provides inconsistent results on the effects of term-time employment on the progress of studies (reviewed in Riggert, Boyle, Petrosko, Ash, \& Rude-Parkins, 2006). However, Broadbridge and Swanson (2007) noted that the overall focus of studies investigating the relationship between "earning and learning" has been on the negative effect of combining these roles. The research suggests that term-time employment leads to poorer adjustment to university life in terms of academic performance, social inclusion, and psychological well-being. Broadbridge and Swanson (2007) argued that it is difficult to draw generalizable conclusions regarding the interrelationship between university life and part-time employment roles. Having young children at home has, however, been found to adversely affect women's (J acobs \& Berkowitz-King, 2002) and both male and female divorced parents' degree completion (Taniguchi \& Kaufman, 2005).

Students with job or family commitments need flexibility in order to organize their everyday lives (Miller \& Lu, 2003). Since multiple commitments may diminish the amount of face-to-face interactions in which they participate, the use of computer-mediated communication (CMC) applications may offer an alternative for study-related communication and collaboration. Earlier studies have indicated that the possibilities offered by Social Networking Sites (SNS) such as Facebook, with multiple ways of communication, play an important role in maintaining and advancing students' social networks (Ellison, Steinfield, Lampe, \& Vitak, 2011), but that online communication is primarily used for maintaining existing ties (Ellison, Steinfield, \& Lampe, 2007). Therefore, without first getting to know their fellow students the possibilities provided by CMC may not be realized for students with multiple commitments.

This is a case study of a Finnish university's students' self-reported use of both synchronous and asynchronous CMC tools for collaboration and communication through laptops and information networks (INs). The main objective of this study is to compare whether and what kinds of differences exist between the perceived use of synchronous and asynchronous CMC tools among students with children or in full-time employment and students without these commitments. Collaboration is defined in this article in its broadest sense as a situation in which two or more people attempt to learn something together (Dillenbourg, 1999). Communication is here defined as any social interaction that is mediated by CMC tools on laptops and INs, i.e. as CMC (J onassen, Davidson, Collins, Campbell, \& Bannan Haag, 1995).

The "digital native" label is often used to explain how young people born after 1980 use technologies, but according to a review of research into university students' use of technology, it may be too simplistic (Margaryan et al., 2011). In their own research, Margaryan and others (2011) found that the use of newer CMC applications such as SNS was low for learning and socializing (and in the U.K. in 2007) and dependent on students' age and discipline. The academic usefulness of SNS was also found to be low in the study by Vrocharidou and Efthymiou (2012). Margaryan and others (2011) concluded that future research should take into consideration a broader range of variables that relate to university students' use of technology, such as students' life circumstances. The study presented here addresses this aim in particular by focusing on students with extra commitments along with their studies. Hence, the specific research questions of this study are as follows:

1. Are there differences in the self-reported use of CMC tools for communicating with peers, instructors, family members, and friends between students with and without a job or family commitments? 
2. Are there differences in the self-reported use of laptops and information networks for collaboration with peers between students with or without a job or family commitments?

\section{University Students' Use of CMC Tools in Communica- tion and Collaboration}

CMC tools can be used for both information exchange and collaboration, as well as to fulfill students' social needs. The tools can be roughly divided into synchronous and asynchronous communication tools. Instant messaging (IM) is one of the most popular of these, but its use has been restricted to one's "real space friends," people whom they first met face-to-face in physical space settings (Grinter \& Palen, 2002; Mesch, 2012). Hu et al. (2004) found that the amount of IM use was positively associated with verbal, affective, and social intimacy and that frequent conversations using IM actually encourage participants to meet face-to-face.

Asynchronous CMC tools include e-mail, discussion boards, and virtual learning environments (VLEs). The advantage of these applications is the opportunity to interact even if arranging a mutually convenient time for interaction is a challenge. Although IM has increased in popularity, especially among younger generations, e-mail still has a broader range of users (J ones \& Fox, 2009). Recchiuti (2003) found that university students made greater use of email in the case of task-related communication, reflecting a more instrumental form of CMC, while IM use was more biased toward socially oriented forms of CMC. According to students, e-mail helps them to express their ideas to instructors better than in face-to-face situations (J ones, 2002).

A central premise of this study is that all use of technology is socially shaped and locally situated. Accondingly, understanding students' use or non-use of technologies requires that we situate their use of technology in the context of their everyday lives, including, for example, their social relationships, life stage and lifestyle (Haythornwaite, 2001). Research results on university students' use of the latest forms of CMC, such as SNS platforms (e.g. Facebook, MySpace), also support these findings.

The latest forms of CMC had not yet reached the mainstream in Finland when this study was conducted in 2008. These sites integrate a combination of asynchronous and synchronous tools (see, e.g., Vrocharidou \& Efthymiou, 2012). Compared to the more traditional forms of CMC, SNSs provide more flexible and personalizable forms of sociability, allowing students to maintain both weak and strong ties more easily (Ellison et al., 2011). In the case of SNS, it seems to be easier to "make friends" even with people who are merely acquaintances.

\section{Pedagogical Challenges and Opportunities in the Use of CMC}

A sense of community is essential for successful e-learning, and the lack of it is experienced as a major challenge by e-learners due to the limited social bonds and social presence among community members (Hung \& Yuen, 2010; cf. Tinto \& Pusser, 2006). Therefore, hybrid communities that mix online interaction with face-to-face interaction may be ideal in terms of developing a sense of community. The use of social networking tools could contribute to university students' positive learning experiences, and these experiences relate to the information-sharing feature and interactional function of technology (Hung \& Yuen, 2010.) 
Research has indicated that peer and tutor support is a motivating force in blended learning settings and it results in improved coursework submission rates (Hughes, 2007). Furthermore, IM conversations among peers have been shown to offer a means of practical and empathetic peer support for students (Timmis, 2012).

Based on the arguments outlined above, students with multiple commitments may benefit from the opportunity of using communication tools in lieu of or in addition to face-to-face communication with their peers and instructors. Their studying is determined by their responsibilities, based on schedules which are often asynchronous to those of their peers and outside the office hours of their instructors. It is probable that they would prefer to make greater use of asynchronous communication and less use of synchronous communication than other students. Further, more frequent use of laptop- and network-aided collaboration by students with multiple commitments could be expected.

In our experience interactions within VLEs are usually instructor-initiated and very often, participation in online discussions is compulsory. Because the social network is already "built into" the course structure, communication within VLEs might be easier than in traditional classroom-based course designs. Students with multiple commitments may also be more eager to select courses that can be carried out in VLEs (Dutton, Dutton, \& Perry, 2002).

\section{Data Collection and Analysis}

This study was conducted at the University of Lapland in Finland, where a laptop program was launched in the autumn of 2004. New students had the option to purchase a laptop partly sponsored by the university. The pedagogical use of laptops is, however, greatly dependent on the field of study, and on individual instructors and students. However, the use of the laptop in teaching depends to a large extent on the field of study undertaken and on individual instructors and students.

Data were collected by means of an online questionnaire inquiring into students' experiences with the laptop program in 2008. As the data were collected some time ago, it is legitimate to question the ongoing validity of this study, especially given that we operate in the field of research into the pedagogical use of ICTs and the technologies are changing rapidly.

However, although technologies change rapidly, this is not necessarily true of people and the ways in which technologies are used in everyday life, particularly in learning processes. Recent research has discovered that university freshmen still use a fairly limited range of technologies (Guo, Dobson, \& Pe trina, 2008; Jones, Ramanau, Cross, \& Healing, 2010; Kennedy, Judd, Churchward, Gray, \& Krause, 2008; Thompson, 2013), and they are not utilizing the Internet to its full potential or critically reviewing the information they obtain (Thompson, 2013).

When assessing the period after the data collection in 2008, the pedagogical practices of applying technologies in teaching and learning processes do not seem to have been developed in sequence. Although young adults enrolling in their university studies use ICTs in their everyday lives, they do not necessarily exploit the opportunities offered by technologies in learning (Thompson, 2013). Students' learning histories do not necessarily include greater experience of using ICTs now than they did prior to 2008.

The questionnaire was generated using the Webropol website (www.webropol.com) and then delivered to students by e-mail. In April 2008, a personal link to the questionnaire was delivered by email to all the 2,888 
students who entered the University of Lapland in the fall of 2004 or later. Some students who had entered the university before the fall of 2004 but had later changed their majors were also included. Reminder emails were sent a week later. The survey measured student experiences and knowledge of using computers and the Internet, as well as experiences with laptops and networks in teaching, studying, and learning.

In the questionnaire that comprised 119 items students were asked to provide background information (e.g., age, marital status, number of children, and work commitments during term-time). Questions regarding students' use of CMC tools and laptop-aided collaboration took the form of multiple-choice questions using a five-point Likert-type scale. The questionnaire was accompanied by an e-mail, in which the research was introduced and students were asked for informed consent. The questionnaire was tested before delivery to students; overlapping questions were eliminated, and the questionnaires were shortened.

The data were analyzed using SPSS version 15.0 (SPSS for Windows). Factor analysis (principal component analysis; varimax rotation) was used to group 14 individual communication- and collaboration-related items into meaningful categories (Table 1). To test whether the student background characteristics have an effect on respondents' self-reported patterns of communication and collaboration, the resultant categories were used to create scales. The internal consistency of the created scales was tested by calculating Cronbach's alpha (Cronbach, 1951). Cronbach's alpha takes values from 0 (indicating no correlation) to 1 (indicating identical results), and an alpha value of about 0.7 or above is considered evidence of acceptable internal consistency (Nunnally, 1978). All scales were recoded into five-point scales for further analysis.

The Kruskal-Wallis $\chi^{2}$ test was applied to analyze the relations between the scales and background information (contingencies). As the Kruskal-Wallis test is not a good indicator of the strength of a relationship and is partially dependent on n, Goodman and Kruskal's tau, an additional measure of association was used (Goodman \& Kruskal, 1954). Goodman and Kruskal's tau follows the proportional-reduction-in-error logic (Reynolds, 1984) and takes values between 0 (no association) and 1 (completely related). When possible, the exact significance was computed-otherwise, a Monte Carlo estimation of the significance based on 10,000 samples was used (Mehta \& Patel, 1996). Statistical differences were deemed significant at $p=0.05$, and each tested association is mentioned as significant in the results section only if both statistical tests used indicate significant results. Correlation analysis (Spearman's rho, $\rho$ ) was used to test correlations between the created scales and data on computer and Internet use.

\section{Respondents}

A total of 575 students opened the link to the online questionnaire in 2008, 183 of whom did not complete the poll. Therefore, only $13.6 \%$ (392) of the whole target population (2,888 students) filled in the questionnaire. Of the 392 respondents, 372 had either a university-sponsored laptop or a laptop of unspecified provenance in their use and were therefore in a position to answer all the questions included in this particular article. One reason for the low response rate was probably the cover letter in which it was stated that the study concerned the use of laptops and wireless networks at the University of Lapland-naturally excluding many students who did not have a laptop and were therefore unable to take advantage of the wireless networks. The proportion of male (26\%) and female (74\%) respondents was fairly representative of the whole target population. Each of the university's four faculties was represented in proportion to its student population. 
The mean age of the respondents was 28.5 years (median $=25$ ), with the youngest students being 20 and the oldest being 59 years old. $22.2 \%$ of respondents had children, $48.5 \%$ were married or cohabiting, $19.1 \%$ were had a partner, and $32.4 \%$ were single. A majority of the students worked during term-time either regularly (34.4\%) or occasionally (39.3\%), while $26.3 \%$ of the respondents did not work at all during their studies.

much have you used laptops and

\section{Results}

First, a factor analysis was conducted in order to group 14 individual communication- and collaboration-related items into meaningful categories. Four factors with corresponding items and eigenvalues over 1.0 emerged from the data (Table 1).

Table 1. Factor analysis (principal components; varimax rotation) results of fourteen items describing students' self-reported computer-mediated communication and laptop- and network-aided collaboration.

\begin{tabular}{|c|c|c|c|c|}
\hline \multirow[b]{2}{*}{ Items } & \multicolumn{4}{|c|}{ Factors } \\
\hline & 1 & 2 & 3 & 4 \\
\hline \multicolumn{5}{|l|}{ Estimate, how much have you used laptops and networks to ... } \\
\hline do group work with your peers while working in the same space? & & .611 & & \\
\hline do group work using e-mail or virtual learning environments? & & .627 & & \\
\hline work on a shared document online with your peers? & & .647 & & \\
\hline work together on a shared idea? & & .801 & & \\
\hline publish information and pass it on to others? & & 679 & & \\
\hline \multicolumn{5}{|l|}{ How often have you used ... } \\
\hline virtual learning environments to communicate with peers? & .807 & & & \\
\hline discussion boards to communicate with teachers? & .789 & & & \\
\hline virtual learning environments to communicate with teachers? & .839 & & & \\
\hline discussion boards to communicate with peers? & .735 & & & \\
\hline instant messaging to communicate with peers? & & & .887 & \\
\hline instant messaging to communicate with family members and friends? & & & .883 & \\
\hline e-mail to communicate with peers? & & & & .771 \\
\hline e-mail to communicate with family members and friends? & & & & .700 \\
\hline e-mail to communicate with teachers? & & & & .679 \\
\hline Cronbach's alpha & 0.841 & 0.749 & 0.790 & 0.628 \\
\hline
\end{tabular}

These four categories were used to create scales that were tested for internal consistency (Cronbach's alpha; Table 1) and named as follows: 1) communication with peers and instructors using VLEs (VLEs), 2) laptop- and information network-aided collaboration with peers (collaboration), 3) communication by IM (IM), and 4) communication by e-mail (e-mail). The actual use of IM with instructors was practically non-existent ( $0.3 \%$ of respondents) and was there fore omitted from the factor analysis.

The factor analysis showed that communication by each communication tool differed somewhat from each other, as communication by each tool was grouped into its own category. However, as Cronbach's alpha for "communication by e-mail" was only 0.628 and a value of 0.7 is considered evidence of acceptable reliability (Nunnally, 1978), communication with peers, instructors, and family members or friends (other than peers) using e-mail were all analyzed individually without creating a common scale. To make the comparison between e-mail and IM use easier, the use of IM with peers, instructors, and 
family members or friends were all analyzed individually. As far as the internal consistencies of the other scales were concerned, the reliability loadings were well above 0.7 (Table 1).

\section{Self-reported Use of CMC for Communicating with Peers, Instructors, Family Members, and Friends}

Significant differences in the self-reported use of e-mail with peers (Table 2) or instructors (Table 3) were not found between students with and without family commitments, employment status, genders, or different age groups. However, Goodman and Kruskal's tau suggests that students working regularly or occasionally might have been somewhat more active users of e-mail for communication with peers than students not working at all. As far as the self-reported e-mail use for communication with family members or friends was concerned, the results indicate that having children, regular employment during termtime, and increasing age all significantly increased e-mail use (Table 4). Gender did not influence the self-reported use of e-mail with family members or friends.

Table 2. Students' self-reported use of e-mail and instant messaging (IM) for communication with peers, and use of virtual learning environments (VLE) for communication with peers and teachers.

\begin{tabular}{|c|c|c|c|c|c|c|c|c|c|}
\hline & \multicolumn{3}{|c|}{ E-mail } & \multicolumn{3}{|c|}{ IM } & \multicolumn{3}{|c|}{ VLE } \\
\hline & Mean (SD) & $x^{2}$ & $\mathrm{~T}$ & Mean (SD) & $x^{2}$ & $\tau$ & Mean (SD) & $x^{2}$ & $\tau$ \\
\hline Have children & & 2.930 & 0.002 & & $65.949 * *$ & $0.073^{* *}$ & & $19.609 * *$ & $0.017^{* *}$ \\
\hline Yes & 3.18 (1.09) & & & 1.58 (1.09) & & & $2.21(0.88)$ & & \\
\hline No & $3.43(1.02)$ & & & $3.26(1.56)$ & & & $1.74(0.72)$ & & \\
\hline Employment & & 3.365 & $0.011 *$ & & $19.778^{* *}$ & $0.026^{* *}$ & & 6.133* & $0.028 * *$ \\
\hline Yes/regularly & 3.36 (1.09) & & & 2.38 (1.63) & & & $1.97(0.77)$ & & \\
\hline Occasionally & 3.48 (1.01) & & & $3.09(1.56)$ & & & $1.76(0.75)$ & & \\
\hline Not at all & $3.25(1.00)$ & & & 3.29 (1.57) & & & $1.78(0.83)$ & & \\
\hline Gender & & 0.128 & 0.002 & & $12.518 * *$ & $0.014^{* *}$ & & 1.352 & 0.001 \\
\hline Male & $3.41(1.00)$ & & & $3.41(1.52)$ & & & $1.74(0.72)$ & & \\
\hline Female & $3.37(1.05)$ & & & 2.73 (1.63) & & & $1.86(0.80)$ & & \\
\hline Age & & 7.562 & 0.009 & & $100.117 * *$ & $0.123^{* *}$ & & $32.203^{* *}$ & $0.035 * *$ \\
\hline $19-20 /<24$ & 3.36 (1.05) & & & 3.70 (1.38) & & & $1.62(0.68)$ & & \\
\hline 21-25? / 24-25 & $3.41(1.04)$ & & & $3.35(1.52)$ & & & $1.69(0.74)$ & & \\
\hline$>25$ / 26-29 & $3.60(0.96)$ & & & $2.87(1.59)$ & & & $1.86(0.77)$ & & \\
\hline$-\quad />29$ & $3.17(1.05)$ & & & 1.55 (1.11) & & & $2.20(0.81)$ & & \\
\hline Total & $3.38(1.04)$ & & & $2.91(1.63)$ & & & $1.83(0.78)$ & & \\
\hline
\end{tabular}

Note: Mean values (SD), the results of the statistical tests (Kruskal-Wallis chi square $=\chi^{2}$ and Goodman and Kruskal's tau $=\tau)$, and their significance $\left({ }^{*}=p<0.05,{ }^{* *}=p<0.01\right)$ are also included.

Differences in the self-reported use of IM for communication with peers (Table 2) and family members or friends (Table 4) were very clear, as students with children, students working during term-time, older students, and female students were all significantly less active users of IM than the rest of the respondents. Only a few students reported having used IM for communication with instructors, and no significant differences were found between students whose life circumstances differed (Table 3).

The self-reported use of VLEs was very low (Table 2). Students with children, students in regular employment, and older students all made greater use of VLEs for communication than other students (Table 2). It should, however, be noted that more than 35\% of all respondents had never used VLEs for communication. Gender had no effect on the self-reported use of VLEs for communication. 
Table 3. Students' self-reported use of e-mail and instant messaging (IM) for communication with instructors.

\begin{tabular}{lcccccc} 
& Mean (SD) & $\chi^{2}$ & $\tau$ & Mean (SD) & $\chi^{2}$ & $\tau$ \\
\cline { 2 - 7 } Have children & & 0.449 & 0.003 & & 0.001 & 0.001 \\
Yes & $2.99(0.93)$ & & & $1.05(0.22)$ & & \\
No & $2.90(0.89)$ & & & $1.08(0.35)$ & & \\
Eesployment & & 2.857 & 0.008 & & 3.321 & 0.010 \\
Occasionally & $3.01(0.98)$ & & & $1.11(0.40)$ & & \\
Not at all & $2.93(0.86)$ & & & $1.05(0.28)$ & & \\
Gender & $2.79(0.82)$ & & & $1.05(0.30)$ & & \\
Male & & 1.928 & 0.004 & & 1.479 & 0.003 \\
Female & $2.82(0.90)$ & & & $1.12(0.46)$ & & \\
Age & $2.95(0.89)$ & & & $1.05(0.27)$ & & \\
19-20 / <24 & & 4.143 & 0.008 & & 5.930 & 0.014 \\
$21-25 ? / 24-25$ & $2.79(0.87)$ & & & $1.04(0.28)$ & & \\
$>25 \quad / 26-29$ & $2.94(0.88)$ & & & $1.03(0.16)$ & & \\
$-\quad />29$ & $3.07(0.92)$ & & & $1.13(0.46)$ & & \\
\hline Total & $2.92(0.90)$ & & & $1.09(0.36)$ & & \\
\hline
\end{tabular}

Note: Mean values (SD), the results of the statistical tests (Kruskal-Wallis chi square $=\chi^{2}$ and Goodman and Kruskal's tau $=\tau$,$) and their significance \left({ }^{*}=p<0.05, * *=p<0.01\right)$ are also included.

Table 4. Students' self-reported use of e-mail and instant messaging (IM) for communication with family members and friends (other than peers).

\begin{tabular}{|c|c|c|c|c|c|c|}
\hline & \multicolumn{3}{|c|}{ E-mail } & \multicolumn{3}{|c|}{ IM } \\
\hline & Mean (SD) & $x^{2}$ & $\tau$ & Mean (SD) & $x^{2}$ & $\tau$ \\
\hline Have children & & $15.582^{* *}$ & $0.011^{* *}$ & & $35.707^{* *}$ & $0.032^{* *}$ \\
\hline Yes & $4.13(0.86)$ & & & $2.71(1.51)$ & & \\
\hline & $3.56(1.12)$ & & & 3.85 (1.31) & & \\
\hline Employment & & $13.586^{* *}$ & $0.022^{* *}$ & & 22.189** & $0.025^{* *}$ \\
\hline Yes/regularly & 3.94 (1.13) & & & 3.08 (1.58) & & \\
\hline Occasionally & 3.59 (1.05) & & & 3.79 (1.27) & & \\
\hline Not at all & 3.48 (1.07) & & & $4.01(1.27)$ & & \\
\hline Gender & & 1.000 & 0.004 & & $6.987^{* *}$ & $0.007 *$ \\
\hline Male & 3.56 (1.21) & & & 3.95 (1.29) & & \\
\hline Female & $3.72(1.06)$ & & & 3.50 (1.46) & & \\
\hline Age & & 27.230 ** & $0.028 * *$ & & $52.770 * *$ & $0.057^{* *}$ \\
\hline $19-20 \quad /<24$ & $3.34(1.04)$ & & & 4.09 (1.16) & & \\
\hline 21-25? / 24- 25 & 3.58 (1.14) & & & 3.87 (1.27) & & \\
\hline$>25$ / 26- 29 & 3.80 (1.05) & & & $3.82(1.19)$ & & \\
\hline$-\quad />29$ & $4.08(1.04)$ & & & 2.58 (1.59) & & \\
\hline Total & $3.68(1.10)$ & & & $3.61(1.43)$ & & \\
\hline
\end{tabular}

Note: Mean values (SD), the results of the statistical tests (Kruskal-Wallis chi square $=\chi^{2}$ and Goodman and Kruskal's tau $=\tau)$, and their significance $\left(^{*}=\mathrm{p}<0.05,{ }^{* *}=\mathrm{p}<0.01\right)$ are also included. 


\section{Self-reported Use of Laptops and Information Networks for Collaboration with Peers}

Having children, employment during term-time, gender or age did not affect the amount of self-reported laptop-aided collaboration. The chi square test suggested that men were slightly more active users of laptops and IN for collaboration, but this was not supported by Goodman and Kruskal's tau.

Table 5. Students' self-reported use of laptops and information networks for collaboration with peers.

\begin{tabular}{lrrr} 
& \multicolumn{3}{c}{ Collaboration } \\
\cline { 2 - 4 } & Mean (SD) & $\chi^{2}$ & $\tau$ \\
\hline Have children & $2.53(0.84)$ & & \\
Yes & $2.64(0.82)$ & & \\
No & & 3.639 & 0.0011 \\
Employment & $2.73(0.88)$ & & \\
Yes/ regularly & $2.57(0.76)$ & & \\
Occasionally & $2.56(0.83)$ & & \\
Not at all & & $4.110 *$ & 0.004 \\
Gender & $2.77(0.87)$ & & \\
Male & $2.57(0.80)$ & & \\
Female & & 1.470 & 0.008 \\
Age & $2.56(0.82)$ & & \\
$19-20$ / <24 & $2.68(0.76)$ & & \\
$21-25 ? / 24-25$ & $2.66(0.82)$ & & \\
$>25 \quad / 26-29$ & $2.60(0.88)$ & & \\
- & $2.62(0.82)$ & & \\
\hline Total / $>29$ &
\end{tabular}

Note: Mean values (SD), the results of the statistical tests (Kruskal-Wallis chi square $=\chi^{2}$ and Goodman and Kruskal's tau $=\tau)$, and their significance $\left({ }^{*}=\mathrm{p}<0.05,{ }^{* *}=\mathrm{p}<0.01\right)$ are also included.

Table 6. Correlations (Spearman) and their significances $(*=p<0.05, * *=p<0.01)$ between computer use measures and the use of CMC tools and computer- and network-aided collaboration.

\begin{tabular}{lrrrrrr}
\hline & \multicolumn{7}{c}{ How often have you used ... } \\
\hline & $\begin{array}{r}\text { Computer } \\
\text { at home }\end{array}$ & $\begin{array}{r}\text { Internet } \\
\text { at home }\end{array}$ & $\begin{array}{r}\text { Computer } \\
\text { on campus }\end{array}$ & $\begin{array}{r}\text { Internet } \\
\text { on campus }\end{array}$ & $\begin{array}{r}\text { Your laptop } \\
\text { on campus }\end{array}$ & $\begin{array}{r}\text { WLAN*** } \\
\text { on campus }\end{array}$ \\
\cline { 2 - 7 } E-mail with peers & $0.162^{* *}$ & 0.175 & $0.204^{*}$ & $0.230^{* *}$ & $0.220^{* *}$ & $0.219^{* *}$ \\
E-mail with instructors & 0.036 & 0.055 & $0.105^{*}$ & 0.089 & 0.099 & 0.088 \\
E-mail with family friends & 0.038 & 0.064 & -0.003 & -0.010 & 0.026 & 0.000 \\
IMing with peers & $0.218^{* *}$ & 0.231 & $0.192^{* *}$ & $0.280^{* *}$ & $0.216^{* *}$ & $0.251^{* *}$ \\
IMing with instructors & 0.016 & 0.029 & 0.091 & 0.103 & $0.133^{*}$ & $0.208^{* *}$ \\
IMing with family members or friends & $0.174^{* *}$ & 0.210 & $0.197^{* *}$ & $0.235^{* *}$ & $0.206^{* *}$ & $0.233^{* *}$ \\
VLEs & -0.043 & 0.001 & 0.102 & 0.051 & $0.207^{* *}$ & $0.142^{*}$ \\
Collaboration & 0.063 & 0.072 & $0.263^{* *}$ & $0.245^{* *}$ & $0.315^{* *}$ & $0.303^{* *}$ \\
\hline
\end{tabular}

***Wireless Local Area Network

The results of the Spearman correlation analysis indicate that most collaborative work with laptops is conducted within the campus area (Table 6). The use of VLEs correlated only with laptop and WLAN use on campus, while the overall use of VLEs for communication was at a very low level and further conclusions based on this data should not be drawn. E-mail use with instructors and family members or friends was the only variable that in no way-or only to a negligible extent-corresponded to computer and Internet use measures. 


\section{Discussion}

This case study has inquired into the extent and nature of Finnish university students' self-reported use of e-mail, IM, and VLEs for both collaboration and communication. The results indicate that students with a job or family commitments, as well as older students, all reported having used significantly more VLEs and significantly less IM for communication than other students. E-mail seems to be an important communication tool for students in general, regardless of their life circumstances, as it was frequently used by all participants. The only differences were to be found in communication between students and their family members and friends.

Other researchers have found that greater use is made of online communication with friends than with family members, probably reflecting a generation gap in technology skills (Baym, Zhang, \& Lin, 2004). In a study carried out by Lo and Leung (2009), a majority of respondents (college students) indicated that they would choose IM rather than e-mail if they were compelled to choose just one medium to communicate with friends and family members. This trend points to a gradual shift in communication from e-mail toward IM and SNS as younger generations have reached higher education institutions.

Neither students' life circumstances nor age had an affect on the self-reported activity of collaboration using laptops and INs, but males collaborated more actively than females. The insignificant differences in the degree of collaboration between students in different life circumstances and age groups indicate that the students with family or work commitments have been successful in using their laptops and INs for collaboration. However, based on the data collected we can only surmise whether students with commitments are still excluded from some of the face-to-face collaboration and are compensating for this deficiency by selecting courses in which priority is given to, for example, VLEs.

Because laptop-aided collaboration correlated most strongly with laptop and wireless local area network (WLAN) use on campus, the results indicate that most collaborative work with laptops is conducted within the campus area or at least between partners who have the opportunity to spend time on campusand therefore the opportunity to establish such social relations with peers that enable successful CMC and collaboration. This is in accordance with the results of Bryant et al. (2006) and Mesch (2009), who suggested that, although CMC may facilitate the formation of new social relationships, its main function is still the maintenance of existing social ties. Whether the courses, in which these student have participated, have been able to foster the creation of these relationships is not known. However, to gain a deeper understanding of factors associated with collaborative work with laptops, one should take into account curricula and pedagogies, both of which shape the use of laptops for collaborative work (e.g., Tinto \& Pusser, 2006).

Instead, in the case of students with extra commitments, the use of VLEs is probably related to the fact that they are keen to select flexible online courses that do not depend on either face-to-face or synchronous online communication (see also Miller \& Lu, 2003). It should be noted that at the time the VLE used in the University of Lapland did not allow synchronous communication between participants. However, when all course students are obliged to participate (e.g., through the conversations that were most often asynchronous in these learning environments during the course) previous social connections might not have such a strong effect on students' communication activity.

Students with a job or family commitments as well as older students used IM significantly less for communication with their student peers than other students. Although the frequency of e-mail use was at the same level among stu- 
dent groups, it should be noted that students without extra commitments probably use more face-to-face communication with their peers, which consequently decreases the need for CMC. Since most students with commitments make frequent use of IM for communication with their family members and friends (Table 4), the low use of IM with their peers (Table 2) suggests that communication through IM requires stronger ties than communication by email. This conclusion is supported by the results of Mesch (2012) indicating that IM is primarily used to maintain existing ties rather than to develop new ones. However, these conclusions do not concur the results of Kim et al. (2007), who studied college students' mean closeness in communication relationships by medium and ranked IM and e-mail use at the same level of closeness. The other explanation for the low frequency of IM use with peers might be that students with commitments find it hard to arrange a mutually convenient time for synchronous communication and collaboration with their student peers, or, that they prefer to study independently and follow their own schedules. Because the motivation for using IM would seem primarily to be social (Quan-Haase, 2008), it is unlikely that the low level of IM use with fellow students has an adverse effect on the successful outcome of the studies undertaken by these students. It could indicate that students with commitments have a low level of social support from their fellow students either by choice or because establishing strong social ties with peers is challenging for them due to their other engagements.

The results of the factor analysis suggest that the use of CMC tools differs from each other. This might be because user characteristics (e.g., personality type) affect the choice of CMC tools (e.g., Wilson, 2000) or because the content of communication (e.g., social vs. study-related communication), on average, differs between these tools (e.g., Mesch, 2009). Although e-mail use with peers, instructors, and family members or friends were all grouped into the same category by the factor analysis, reliability tests (Cronbach's alpha) indicated their incompatibility for a common scale, as the amount of e-mail use was clearly dependent on the target of communication. It therefore seems not only that students' use of CMC tools depends on the students' background and the target of communication but also that the content of communication has an effect on the choice of CMC tools used.

On the basis of the study presented here it can be concluded that university students' individual life circumstances have an effect on how they use CMC tools for communication. The practical implication of the study is that pedagogical choices should support different kinds of learning strategies. Students with multiple commitments, and especially students with children, should be encouraged and assisted to create stronger ties with their peers, if they are willing to do so. Sometimes it may be more convenient to conduct studies individually without having to negotiate timetables and distribution of work in a condition that is largely dictated by other commitments. Further research, however, is needed to clarify and explain this topic.

When interpreting these results, one should remember that this is a case study, so all respondents come from one university. In addition, the survey is not representative of the experiences across the whole student population in the university but only those actively using computers and INs, so generalizations should be made with caution.

\section{Acknowledgements}

The results reported here are part of the MobIT project (Developing Mobile Network-based Teaching, Studying and Learning Processes) surveying university students' expectations and experiences of laptop computers and networks. The project was funded by the Ministry of Education for the years 2007- 09. 


\section{References}

Broadbridge, A., \& Swanson, V. (2007). Earning and learning: How term-time employment impacts students' adjustment to university life. J ournal of Education and Work, 18(2), 235- 249.

Bryant, J . A., Sanders-J ackson, A., \& Smallwood, A. M. K. (2006). IMing, text messaging and adolescent social networks. Journal of Computer Mediated Communication, 11(2), 577- 592.

Cronbach, L. J. (1951). Coefficient alpha and the internal structure of tests. Psychometrika, 16(3), 297-334.

Dillenbourg, P. (1999). What do you mean by collaborative learning? In Collaborative learning: Cognitive and computational approaches. P. Dillenbourg (Ed). (pp. 1- 19). Oxford: Elsevier.

Dutton, J., Dutton, M., \& Perry, J. (2002). How do online students differ from lecture students? J ournal of Asynchronous Learning Networks, 6(1), 1-20.. Retrieved from http:// uwf.edu/ATC/ Guide/PDFs/how online students differ.pdf

Ellison, N. B., Lampe, C., Steinfield C., \& Vitak, J. (2011). With a little help from my friends: How social network sites affect social capital processes. In The networked self: Identity, community and culture on social network sites. Z. Papacharissi (Ed.) (pp. 124- 146). New York, NY: Routledge.

Ellison, N. B., Steinfield, C., \& Lampe, C. (2007). The benefits of Facebook 'friends:' Social capital and college students' use of online social network sites. J ournal of Computer-Mediated Communication, 12(4), 1143- 1168.

Ellison, N. B., Steinfield, C., \& Lampe, C. (2011). Connection strategies: Social capital implications of Facebook-enabled communication practices. New Media \& Society, 13(6), 873- 892.

Eriksson, M. J., Vuojärvi, H., \& Ruokamo, H. (2009). Laptop computers and wireless university campus networks: Is flexibility and effectiveness improved? Australasian J ournal of Educational Technology, 25(3), 322- 335.

Goodman, L. A., \& Kruskal, W. H. (1954). Measures of association for cross classifications. J ournal of the American Statistical Association, 49(268), 732- 764.

Graham, S., \& Donaldson, J . F. (1999). Adult students' academic and intellectual development in college. Adult Education Quarterly, 49(3), 147- 161.

Grinter, R., \& Palen, L. (2002). Instant messaging in teen life. In Proceedings of the 2002 ACM Conference on Computer Supported Cooperative Work, 21-30. New Orleans, LA: ACM, 2002. Retrieved from http:// douri.sh/classes/readings/GrinterPalen-IMTeenLifeCSCW02.pdf

Guo, R. X., Dobson, T., \& Petrina, S. (2008). Digital natives, digital immigrants: An analysis of age and ICT competency in teacher education. J ournal of Educational Computing Research, 38(3), 235- 254.

Haythornwaite, C. (2001). Introduction: The Internet in everyday life. American Behavioral Scientist, 45(3), 363- 382.

Hoskins, S. L., \& van Hooff, J. C. (2005). Motivation and ability: Which students use online learning and what influence does it have on their achievement? British J ournal of Educational Technology, 36(2), 177- 192.

Hu, Y., Fowler-Wood, J., Smith, V., \& Westbrook, N. (2004). Friendship through IM: Examining the relationship between IM and intimacy. Journal of Computer Mediated Communication, 10(1). Retrieved from http://onlinelibrary.wiley.com/doi/10.1111/j.10836101.2004.tb00231.x/full 
Hughes, G. (2007). Using blended learning to increase learner support and improve retention. Teaching in Higher Education, 12(3), 349- 363.

Hung, H.-T., \& Yuen, S. C.-Y. (2010). Educational use of social networking technology in higher education. Teaching in Higher Education, 15(6), 703- 714.

J acobs, J . A., \& Berkowitz King, R. (2002). Age and college completion: A life-history analysis of women aged 15-44. Sociology of Education, 75(3), 211- 230.

J onassen, D., Davidson, M., Collins, M., Campbell, J., \& Bannan Haag, B. (1995). Constructivism and computer-mediated communication in distance education. American J ournal of Distance Education, 9(2), 7- 26.

Jones, S. (2002). The Internet goes to college: How students are living in the future with today's technology. Retrieved from http:// www.pewinternet.org/ / media// Files/Reports/2002/PIP College Report.pdf.pdf

Jones, S., \& Fox, S. (2009). Generations online in 2009. Retrieved from http:// www.pewinternet.org/ / media// Files/Reports/2009/PIP Generations 2009.pdf

J ones, C., Ramanau, R., Cross, S., \& Healing, G. (2010). Net generation or digital natives: Is there a distinct new generation entering university? Computers \& Education, 54(3), 722- 732.

Kennedy, G. E., Judd, T. S., Churchward, A., Gray, K., \& Krause, K.-L. (2008). First year students' experiences with technology: Are they really digital natives? Australasian J ournal of Educational Technology, 24(1), 108- 122.

Kim, H., Kim, G. J., Park, H. W., \& Rice, R. E. (2007). Configurations of relationships in different media: FtF, email, instant messenger, mobile phone, and SMS. J ournal of Computer-Mediated Communication, 12(4), 1183- 1207.

Lo, O. W. Y., \& Leung, L. (2009). Effects of gratifications-opportunities and gratifications-obtained on preferences of IM and e-mail among college students. Telematics and Informatics, 26(2), 156- 166.

Margaryan, A., Littlejohn, A., \& Vojt, G. (2011). Are digital natives a myth or reality? University students' use of digital technologies. Computers \& Education, 56(2), 429-440.

Mehta, C. R., \& Patel, N. T. (1996). SPSS Exact Tests'M 7.0 for Windows. Armonk, NY: SPSS.

Mesch, G. S. (2009). Social context and communication channels choice among adolescents. Computers in Human Behavior, 25(1), 244- 251.

Mesch, G. S., Talmud, I., \& Quan-Haase, A. (2012). Instant messaging social networks: Individual, relational, and cultural characteristics. J ournal of Social and Personal Relationships, 29(6), 736- 759.

Miller, M. T., \& Lu, M.-Y. (2003). Serving non-traditional students in e-learning environments: Building successful communities in the virtual campus. Teaching in Higher Education, 40(1), 163- 169.

Münzer, S. (2003). An evaluation of synchronous co-operative distance learning in the field: The importance of instructional design. Educational Media International, 40(1- 2), 91- 100.

Nunnally, J . C. (1978). Psychometric theory (2nd ed.). New York, NY: McGraw-Hill.

Quan-Haase, A. (2007). University students' local and distant social ties: Using and integrating modes of communication on campus. Information, Communication \& Society, 10(5), 671- 693. 
Quan-Haase, A. (2008). Instant messaging on campus: Use and integration in university students' everyday communication. The Information Society, 24(2), 105- 115.

Recchiuti, K. (2003). College students' uses and motives for e-mail, IM, and online chat rooms. (Unpublished master's thesis) University of Delaware.

Reynolds, H. T. (1984). Analysis of nominal data (2nd ed.). Beverly Hills, CA: Sage.

Riggert, S. C., Boyle, M., Petrosko, J. M., Ash, D., \& Rude-Parkins, C. (2006). Student employment and higher education: Empiricism and contradiction. Review of Educational Research, 76(1), 63-92.

Taniguchi, H., \& Kaufman, G. (2005). Degree completion among nontraditional college students. Social Science Quarterly, 86(4), 912-927.

Thompson, P. (2013). The digital natives as learners: Technology use patterns and approaches to learning. Computers \& Education, 65(1), 12- 33.

Timmis, S. (2012). Constant companions: Instant messaging conversations as sustainable supportive study structures amongst undergraduate peers. Computers \& Education, 59(1), 3- 18.

Tinto, V., \& Pusser, B. (2006). Moving from theory to action: Building a model of institutional action for students' success. Retrieved from 2013. http:// web.ewu.edu/groups/academicaffairs/IR/NPEC 5 Tinto Pusser Report.pdf

Vrocharidou, A., \& Efthymiou, I. (2012). Computer mediated communication for social and academic purposes: Profiles of use and university students' gratifications. Computers \& Education, 58(1), 609- 616.

Wilson, E. V. (2000). Student characteristics and computer-mediated communication. Computers \&Education, 34(2), 67- 76.

\section{Biographies}

Miikka Eriksson, $\mathrm{PhD}$, received his $\mathrm{PhD}$ from the University of J oensuu, Finland, in 2007. His doctoral thesis focused on forest ecology, but since then he has conducted research into mobile ICTs in teaching and learning both in vocational and higher education. His research interests include primary and higher education pedagogy and especially the pedagogy of science education as well as the use of mobile ICTs in teaching and learning. Currently he is a University Lecturer in Biology and Geography in the University of Eastern Finland's Philosophical Faculty, School of Applied Educational Science and Teacher Education.

Päivi Rasi (previously Hakkarainen), $\mathrm{PhD}$, MSSc, Title of Docent, received her $\mathrm{PhD}$ from the University of Lapland, Finland, in 2007. Her doctoral thesis focused on the educational use of digital videos for supporting meaningful learning. Currently she is University Lecturer in Adult and Vocational Teacher Education at the University of Lapland's Faculty of Education. Her research interests include higher education pedagogy; ICTs and moving images in teaching and learning; online teaching and learning; and Internet in elderly people's everyday life. Previously she worked as university lecturer in Media Education, and project manager and researcher in several national and international research and development projects encouraging the educational use of ICTs. She has published her research in international scientific journals and compilation works. For further information, please visit:

http:// paivihakkarainen.wordpress.com

Hanna Vuojärvi, $\mathrm{PhD}$, received her $\mathrm{PhD}$ from the University of Lapland, Finland, in 2013. Her doctoral thesis focused on conceptualizing personal and 
mobile learning environments in higher education from university students' point of view. She is currently University Lecturer in Media Education at the University of Lapland's Faculty of Education, Centre for Media Pedagogy. Her research interests include learning environments; decentralized and mobile simulations in health care education; and mobile ICTs in teaching and learning. Previously she has worked as a Lecturer of Information Technology at the Department of Research Methodologies and as a Researcher and a Project Manager in projects focusing on educational use of mobile ICTs in vocational and higher education, and simulation pedagogy in medical education. She has published several international peer-reviewed articles and chapters in books. For further information, please visit:

http:// hannavuojarvi.wordpress.com 